\title{
Villa-Lobos e o Modernismo da Primeira República
}

\author{
Lutero Rodrigues \\ Universidade Estadual Paulista/ Instituto de Artes \\ luterodrigues@gmai.com
}

Resumo: Embora o que é reconhecido como Modernismo no Brasil tenha sido iniciado com a Semana de Arte Moderna de 1922, impondo-se à cultura do país e obrigando tudo aquilo que o antecedeu a ser visto segundo sua ótica exclusiva, a atividade cultural anterior, a partir da República, tivera características próprias e diferenciadas que não poderiam ser negligenciadas. Este trabalho pretende questionar a visão de um único Modernismo, tomando Villa-Lobos como figura central, já que o compositor atuou nos anos anteriores à Semana, e depois dela, tornou-se o principal nome da música nacionalista brasileira. Palavras-chave: Villa-Lobos. Música brasileira. Modernismo. Nacionalismo musical.

\section{Villa-Lobos and The Modernism of First Republic in Brazil}

Abstract: The Brazilian art, from the Republic onwards, have had its own features that couldn't be neglected, even if the Brazilian modernism tries to impose its own version of the preceding artistic efforts, after de Semana de Arte Moderna [Week of Modern Art] in 1922. This paper intends to challenge the unified modernist assumption, taking Villa-Lobos as a central subject. Villa-Lobos had been active sometime before the Week, and after that, he became the main personality of the Brazilian national music. Keywords: Villa-Lobos. Brazilian music. Modernism. Musical nationalism.

\section{Rio de Janeiro e o Modernismo carioca}

Durante o IX Simpósio Internacional de Musicologia da EMAC, Universidade Federal de Goiás, ocorrido em junho de 2019, apresentamos o trabalho "A periodização modernista e os compositores da Primeira República" que se encontra em vias de ser publicado nos anais do evento. Ali questionamos a imposição à História, do movimento iniciado com a Semana de Arte Moderna de 1922, como único e verdadeiro Modernismo. Eminentes intelectuais já demonstraram algum estranhamento em relação à visão oficial dos acontecimentos:

O que a crítica nacional chama de Modernismo está condicionado por um acontecimento, isto é, por algo datado, público e clamoroso, que se impôs à atenção da nossa inteligência como um divisor de águas: A Semana de Arte Moderna, realizada em fevereiro de 1922, na cidade de São Paulo. Como os promotores da Semana traziam, de fato, ideias estéticas originais em relação às nossas últimas correntes literárias, já em agonia, o Parnasianismo e o Simbolismo, pareceu aos historiadores da cultura brasileira que modernista fosse adjetivo bastante para definir o estilo dos novos, e Modernismo tudo o que se viesse a escrever sob o signo de 22 (BOSI, 2013, p. 323). 
Amparados em estudos de diversas áreas, com destaque da História e Literatura, propusemos então a existência de um Primeiro Modernismo, compreendendo os anos da Primeira República até 1922, tendo a cidade do Rio de Janeiro como centro referencial, assim como o Segundo Modernismo terá, inicialmente, a cidade de São Paulo como centro, irradiando-se posteriormente para Minas Gerais, alguns estados do Nordeste e o próprio Rio de Janeiro, capital da República.

Ao início do século XX, foi realizada uma grande reforma urbana no Rio de Janeiro, obrigando a população mais pobre a retirar-se de uma área central da cidade que foi totalmente reurbanizada, tomando-se como modelo a cidade de Paris que também passara anteriormente por semelhantes reformas. Paris e a França dominavam o imaginário da elite econômica e social da cidade, a ponto das pessoas cumprimentarem-se em francês, ao início da Primeira Guerra Mundial (SEVCENKO, 2003, p. 51-2). Desde o século anterior, com o fluxo imigratório estimulado durante o Império, o Rio de Janeiro tornouse uma cidade cada vez mais cosmopolita.

$\mathrm{Na}$ área musical, havia muito interesse por concertos com artistas e repertório europeus. Em se tratando da estreia de obras internacionais contemporâneas, um recente levantamento realizado, circunscrito àquele período, demonstra que havia supremacia absoluta da música francesa (CORRÊA do LAGO, 2010, p. 65-7). Os mais renomados compositores brasileiros em atividade viviam no Rio de Janeiro e quase todos eles estudaram na França, ou tiveram forte vínculo com sua música: Alberto Nepomuceno (1864-1920), Henrique Oswald (1852-1931), Leopoldo Miguez (1850-1902) e Francisco Braga (1868-1945). Dentre os novos compositores que surgiam, destacavam-se: Glauco Velasquez (1884-1914), Luciano Gallet (1893-1931) e Heitor Villa-Lobos (1887-1959).

Ao contrário do trabalho de Goiás, doravante nosso texto evitará sair, sempre que possível, do terreno musical. Portanto, cumpre-nos mencionar as principais características da música produzida, dentre outros, pelos compositores mencionados que integraram, naquele período, o que denominamos Primeiro Modernismo, assim como especificidades do contexto que possibilitaram sua existência, além de algumas possíveis comparações com o Modernismo de 1922. As características mais marcantes foram o internacionalismo e a atualização com a Europa, tendo a França como suprema referência. Isto significava limitar-se à atualização com a música francesa, vendo a música de outros 
países europeus através da França, tal como ocorreu com o wagnerismo que não nos veio diretamente da Alemanha (VIDAL, 2011, p. 279).

No entanto, tanto a influência francesa quanto a wagneriana encontravam-se igualmente nas obras dos compositores acima citados. Numa mesma obra de maior dimensão ambas poderiam ser encontradas, tal como ocorre na ópera $\mathrm{Abul}$, de Alberto Nepomuceno, onde estão presentes motivos condutores wagnerianos, cromatismo que se aproxima de Alban Berg, escalas de tons inteiros (GOLDBERG, 2007, p. 105-6), ou ainda um leque maior de influências: “[...] Nepomuceno realiza em sua ópera uma síntese de elementos estilísticos absorvidos das escolas alemãs, italianas e francesas" (SOUZA, 2014, p. 259).

Nesse universo internacionalista, tampouco estava descartada a música que utilizasse elementos brasileiros provenientes da cultura popular; somente não era uma de suas prioridades. Ali se inserem as primeiras tentativas de Villa-Lobos e Gallet com música brasileira que não chegam a ser numerosas. No entanto, experiências similares de Alexandre Levy (1864-1892) e Alberto Nepomuceno, ao final do século XIX, o segundo em pleno território europeu, devem ser creditadas a uma tardia consequência do Romantismo, como diversos autores já o denunciaram (AZEVEDO, 1956, p. 21).

Quanto ao contexto que favoreceu a existência do Modernismo carioca - devendose frisar que não foi um movimento isolado da área musical, embora esta seja o limite do nosso estudo - o centro de referências foi o Instituto Nacional de Música. Ali atuaram como professores todos os quatro nomes que encabeçam a lista de compositores citados. Além da cordial relação que mantinham entre si, integravam um ambiente muito mais amplo, composto por críticos musicais e numerosos intérpretes, instrumentistas e cantores, todos eles com um perfil não conservador perante a música contemporânea (CORRÊA do LAGO, 2010, p. 252). Os quatro compositores desfrutaram de grande nomeada, porém nunca deixaram de ser receptivos aos três jovens compositores citados, estimulando-os e abrindo caminhos para suas realizações musicais.

O Modernismo de 1922 foi marcado por um evento fundador, a Semana de Arte Moderna, compreendendo somente três noites de espetáculos, nos dias 13, 15 e 17 de fevereiro, caracterizados por polêmicas, escândalos e controversa participação popular que agregava manifestantes contrários e favoráveis ao evento. Consolidou-se ao longo 
dos anos através da enorme difusão que recebeu, incluindo a produção bibliográfica de seus participantes e novos adeptos, simpatizantes da mesma causa. No Primeiro Modernismo, ao contrário, não houve um evento inaugural, escândalos, e a controvérsia ficou a cargo de alguns críticos musicais conservadores já amplamente conhecidos. O público era aquele habitual dos concertos e o repertório não contradizia sua expectativa, tornando maior seu imediato alcance popular.

Contou também com alguns grandes eventos, não programados especificamente pelo movimento, mas dirigidos por seus líderes, como Alberto Nepomuceno. O maior exemplo foi a série de vinte e seis concertos sinfônicos da Exposição Nacional de 1908, na Praia Vermelha, realizados durante dois meses, apresentando um amplo repertório contemporâneo internacional e nacional, até então desconhecido do público brasileiro. As referências ao evento, mesmo sem a grandiosidade bombástica da Semana de Arte Moderna, encontram-se em nossa historiografia: "Pode-se dizer que, em música, foi essa a nossa entrada oficial no século XX" (AZEVEDO, 1956, p. 171).

Como o Modernismo de 1922 conseguiu impor-se, graças à conjunção de diversos fatores culturais, políticos, sociais, e legitimar-se através da imensa produção bibliográfica que gerou, tudo o que denominamos Primeiro Modernismo perdeu seu lugar na história enquanto Modernismo, tornando-se somente um agrupamento mais ou menos disforme de florações artísticas internacionalizantes, renomeadas segundo o ponto de vista do único e "verdadeiro" Modernismo, geralmente com conotações passadistas.

\section{Consequências do Modernismo de 22 e Villa-Lobos}

Diversos estudiosos do que passou a ser o Modernismo oficial afirmam que a primeira importante mudança de rumos do movimento surgiu em 1924, deixando de priorizar a renovação estética em favor da busca do caráter nacional das expressões artísticas. Tornou-se imperativo "[...] elaborar um projeto de cultura nacional em sentido amplo" (MORAES, 1978, p. 73). Nos anos seguintes surgiram diversas obras da nossa historiografia musical e seus autores estavam comprometidos com os novos ideais do Modernismo nacionalista. Suas obras passavam a avaliar os compositores que integraram o movimento anterior com novos critérios, qualificando-os segundo suas afinidades com o nacionalismo musical. 
Foi assim que Leopoldo Miguez e Henrique Oswald são considerados “compositores de coração europeu” (AZEVEDO, 1956, p. 105)), ao mesmo tempo em que Alexandre Levy e Alberto Nepomuceno, que realizaram incursões na música com elementos nativos brasileiros sob o influxo do Romantismo europeu, ascendem ao honroso posto de "precursores" do nacionalismo musical brasileiro (ALMEIDA, 1926, p. 99,115). Luciano Gallet e Heitor Villa-Lobos, jovens coadjuvantes na década anterior, adquirem grande importância. Gallet teve sua promissora carreira interrompida pela morte prematura, em 1931, e Villa-Lobos tornou-se o maior representante do Modernismo nacionalista brasileiro.

\section{José Miguel Wisnik, revelando a influência francesa}

No entanto, foi necessário passar meio século para que José Miguel Wisnik revelasse com maior contundência a forte influência francesa sobre Villa-Lobos, discutindo sua produção musical apresentada na Semana de Arte Moderna, que não era outra senão aquela produzida na década anterior, sob o influxo do que já denominamos Primeiro Modernismo, movimento desconsiderado por nossa historiografia oficial e, naturalmente, pelo próprio autor do trabalho. Seu texto foi "originalmente apresentado como dissertação de mestrado à Universidade de São Paulo" (WISNIK, 1977, p. 4), em 1974, e publicado três anos mais tarde:

A Semana não deve ser entendida como a amostra por excelência do modernismo de Villa-Lobos mas, coroando uma fase de produções que inclui obras de 1914 a 21, apresenta as matrizes de sua evolução imediatamente posterior, quando os traços mais particulares efetivamente se aprofundam, e o compositor deixa em definitivo a órbita debussysta para intensificar a liberação sonora que suas obras faziam esperar (WISNIK, 1977, p. 163).

A repercussão da obra foi grande e imediata, assunto com o qual nos ocuparemos adiante, mas a bombástica revelação já havia sido mencionada, anos antes, por autores modernistas com cuidadosa discrição, pois a nenhum deles interessava ressaltar o passado francófilo do compositor, e sim enaltecer sua produção nacionalista. Mário de Andrade, em "Evolução Social da Música no Brasil”, de 1939, foi um dos primeiros a escrever:

Poucos anos depois de finda a guerra, e não sem ter antes vivido a experiência bruta da Semana de Arte Moderna, de São Paulo, Villa-Lobos abandonava consciente e sistematicamente o seu internacionalismo afrancesado, para se tornar o iniciador e figura máxima da Fase Nacionalista em que estamos (ANDRADE, 1991, p. 25). 
Logo em seguida, Renato Almeida referiu-se à “[...] sua primeira fase, ainda sob a influência dos impressionistas, [...]" (ALMEIDA, 1942, p. 454). Houve até quem ousasse negá-lo, embora conhecesse, certamente, tais referências, preferindo ressaltar suas ousadias musicais, enquanto também reconhecia alguma atitude modernista antes da Semana de Arte Moderna:

\begin{abstract}
As obras que então escrevia já tinham um sabor de agreste modernismo que ultrapassara, consideravelmente, as pálidas tentativas de Glauco Velasquez. O impressionismo de Debussy, que ele só veio a conhecer tardiamente, nenhuma influência exerceu sobre a sua música; o clima refinado, $\mathrm{o}$ aristocrático abandono dessa arte, nada tinham em comum com a expressão direta e brutal do jovem compositor brasileiro, sobre o qual o verismo italiano, este sim, chegara a imprimir a sua marca no período em que Villa-Lobos ainda procurava encontrar os seus próprios caminhos (AZEVEDO, 1956, p. 254).
\end{abstract}

Manifestações modernistas anteriores foram descartadas totalmente perante a imposição do Modernismo de 1922. Entretanto, a leitura da História do Modernismo Brasileiro, de Mário da Silva Brito, sobretudo sua primeira parte denominada "Antecedentes da Semana de Arte Moderna", permite ver que, antes da Semana, os modernistas saíram em busca de artistas de diversas áreas que porventura pudessem ser "descobertos", visando recrutá-los para seu grupo e assim dar maior representatividade ao movimento. Foi o que ocorreu com a pintora Anita Malfatti e o escultor Victor Brecheret, entre outros; ambos já produziam obras que poderiam ser consideradas modernistas, ampliando o movimento (BRITO, 1964, p. 114).

O que se passou com Villa-Lobos não foi diferente. Mesmo que a Semana tenha sido claramente um evento de iniciativa paulista, foi necessário recorrer a músicos do Rio de Janeiro para representar esta atividade artística. Convidá-los significava que naquela cidade havia um compositor que poderia ser considerado moderno e instrumentistas capazes de realizar sua música, aclimatados a uma prática musical que ali se desenvolvia. É o reconhecimento de que o Rio de Janeiro possuía um representativo movimento musical, e o que eles irão apresentar em São Paulo era o que já realizavam no Rio, ou seja, música com forte influência francesa! Embora considerando-se, a partir de então, os únicos modernistas, tal convite demonstrava a existência de um Modernismo anterior. 


\title{
Bruno Kiefer e a análise de procedimentos técnicos
}

Logo após a publicação do trabalho de Wisnik surgiu o livro Villa-Lobos e o Modernismo na Música Brasileira, em 1981, escrito por Bruno Kiefer (1923-1987), compositor alemão cuja família emigrou para o Brasil quando ele tinha apenas 11 anos de idade, passando a viver no Rio Grande do Sul. A obra concentra-se na produção musical de Villa-Lobos anterior à Semana de 22, configurando-se como resultado da repercussão do texto do autor paulista.

Kiefer realiza a análise musical de algumas dezenas de composições que se encontram no catálogo de obras do compositor, produzidas entre 1910 e 1921 . O início do livro também se dedica a descrever aspectos da vida musical do Rio de Janeiro daquele período, destacando o contexto em que as obras foram criadas. Algumas informações são comuns ao nosso texto, como a grande influência europeia e hegemonia francesa que ali imperavam.

\begin{abstract}
Ao analisarmos o quadro sinótico elaborado na base do registro de diversos aspectos das composições examinadas, ressalta uma evidência: a profunda e longa influência exercida pela música francesa, seja pós-romântica, seja impressionista (Debussy). Esta influência foi mais poderosa que qualquer outra. [...] As referidas influências deram-se ou foram procuradas por VillaLobos, aqui no Brasil, mormente no Rio, pois o compositor nunca saíra do País antes de 1922 (a estada de alguns dias na ilha de Barbados não tem a menor significação) (KIEFER, 1986, p. 34, 36).
\end{abstract}

Nos comentários analíticos do autor destaca-se a ocorrência mais frequente de alguns procedimentos técnicos utilizados pelo compositor em suas obras, especialmente a escala de tons inteiros que não é exclusividade dos franceses, mas seu emprego chega a ser um aspecto característico de Debussy (KIEFER, 1986, p. 33). Tal escala está presente em numerosas obras de Villa-Lobos mencionadas, inclusive naquelas em que ele já se aproximava das futuras realizações de música brasileira, como as Danças Características Africanas (1914/15), obra que será apresentada na Semana de 22, em transcrição para octeto instrumental.

A escala de tons inteiros é um recurso técnico que Villa-Lobos continuará empregando na década de 1920, já em pleno período do Modernismo nacionalista, porém cada vez com menor frequência. Os demais compositores nacionalistas evitaram seu emprego ou fizeram-no só de maneira eventual, possivelmente porque conotava a música francesa. É empregada também por Villa-Lobos no poema sinfônico Amazonas, obra 
ousada e atonal estreada em Paris, em 1929, que resultou da completa reformulação do poema sinfônico Myremis (1916). Mário de Andrade ficou muito impressionado com Amazonas, por ocasião de sua estreia em São Paulo, em 1930: "É toda uma orquestra que avança arrastando-se pesada, quebrando galhos, derrubando árvores e derrubando tonalidades e tratados de composição” (ANDRADE, 1976, p. 154,157).

O emprego da politonalidade é menos frequente, mas também ocorre em algumas obras, destacando-se o Trio $n^{\circ} 3$ (1918). Outro autor atribui tal emprego à influência do jovem compositor francês Darius Milhaud (1892-1974) que estava no Brasil, estendendo esta influência a algumas outras composições do mesmo período, nas quais Villa-Lobos utilizou semelhante procedimento (CORRÊA do LAGO, 2010, p. 244). Por fim, há algumas obras que Kiefer simplesmente as denomina "impressionistas", tal a proximidade que guardam de suas homônimas francesas. São os casos do ciclo de canções Historietas (1920), em que predominam textos poéticos em francês, e os textos em português também trazem a tradução para aquela língua, além da peça para piano $A$ Fiandeira (1921) (KIEFER, 1986, p. 39-41).

Parte significativa da historiografia musical brasileira surgida após a Semana de Arte Moderna preferiu ver a primeira produção musical de Villa-Lobos, anterior a 1922, com os olhos do Modernismo oficial que se instalou a partir de então, ressaltando somente sua ousadia e originalidade no contexto brasileiro. Ao final do século XX, percebeu-se que aquela música estava impregnada de influência francesa, fato ignorado anteriormente porque contradizia as prioridades nacionalistas do movimento dominante e foi olvidado. No entanto, a mesma música estava sim atualizada, em conformidade com o pensamento de um outro movimento cuja existência foi apagada da história: o Modernismo carioca da Primeira República ou, como o denominamos, Primeiro Modernismo brasileiro.

\section{Referências}

ALMEIDA, Renato. História da música brasileira. Rio de Janeiro: Briguiet, 1926. História da música brasileira. 2.ed. cor. e aum. Rio de Janeiro: Briguiet, 1942.

ANDRADE, Mário de. Aspectos da música brasileira. Belo Horizonte: Villa Rica, 1991. . Música, doce música. 2. Ed. São Paulo: Martins; Brasília: INL, 1976. 
AZEVEDO, Luiz Heitor Correia de. 150 anos de música no Brasil. Rio de Janeiro: José Olympio, 1956.

BOSI, Alfredo. História concisa da literatura brasileira. 49.ed. São Paulo: Cultrix, 2013.

BRITO, Mário da Silva. História do modernismo brasileiro: antecedentes da Semana de Arte Moderna. 2.ed. Rio de Janeiro: Civilização Brasileira, 1964.

CORREAA do LAGO, Manoel Aranha. O Círculo Veloso-Guerra e Darius Milhaud no Brasil: Modernismo musical no Rio de Janeiro antes da Semana. Rio de Janeiro: Reler, 2010.

GOLDBERG, Luiz Guilherme. Um Garatuja entre Wotan e o Fauno: Alberto Nepomuceno e o Modernismo Musical no Brasil. Tese de Doutorado. Instituto de Artes da Universidade Federal do Rio Grande do Sul, 2007. Porto Alegre, 2007. 205p.

KIEFER, Bruno. Villa-Lobos e o Modernismo na música brasileira. 2.ed. Porto Alegre: Movimento; Brasília: INL: Fundação Nacional Pró-Memória, 1986.

MORAES, Eduardo Jardim de. A brasilidade modernista: sua dimensão filosófica. Rio de Janeiro: Graal, 1978.

SEVCENKO, Nicolau. Orfeu extático na metrópole: São Paulo, sociedade e cultura nos frementes anos 20. São Paulo: Companhia das Letras, 1992.

SOUZA, Rodolfo Coelho de. A influência de Wagner e Verdi na marcha processional e na dança ritual de "Abul" de Nepomuceno. In: SIMPÓSIO INTERNACIONAL DE MUSICOLOGIA DA UFRJ "VERDI, WAGNER E CONTEMPORÂNEOS", 2014, Rio de Janeiro. Anais... Rio de Janeiro, UFRJ, 2014, p. 259-78.

VIDAL, João Vicente. Formação Germânica de Alberto Nepomuceno: Estudos sobre Recepção e Intertextualidade. Tese de Doutorado. Escola de Comunicações e Artes da Universidade de São Paulo, 2011. São Paulo, 2011. 310p.

WISNIK, José Miguel. O coro dos contrários: a música em torno da semana de 22. São Paulo: SCCT; Duas Cidades, 1977. 